\title{
Relationship of Helicobacter pylori seroprevalence with the occurrence and severity of psoriasis*
}

\author{
Priscila Miranda Diogo Mesquita ${ }^{1}$ \\ Miguel Tanus Jorge ${ }^{1}$ \\ Sônia Antunes de Oliveira Mantese ${ }^{3}$
}

\author{
Augusto Diogo Filho \\ Alceu Luiz Camargo Villela Berbert ${ }^{3}$ \\ José Joaquim Rodrigues ${ }^{3}$
}

DOI: http://dx.doi.org/10.1590/abd1806-4841.20174880

\begin{abstract}
BACKGROUND: Psoriasis is a chronic inflammatory disease that affects the skin and joints and has a multifactorial etiology. Recently, it has been suggested that Helicobacter pylori infection may contribute as a trigger for the development of the disease.

Овјестіves: To determine the prevalence of $H$. pylori seropositivity in patients with psoriasis and to evaluate the relation between disease severity and $H$. pylori infection.

Methods: H. pylori infection was assessed in psoriatic patients and controls by using H. pylori IgG quantitative enzyme immunoassay (ELISA test). The patients were classified according to the severity of the disease (PASI score).

Results: One hundred and twenty six patients with psoriasis (73 females and 53 males); mean age 50.48 years; 65 patients $(51.59 \%)$ had severe psoriasis, $40(31.75 \%)$ moderate psoriasis and $21(16.67 \%)$ mild psoriasis. Twenty one healthy volunteers included as a control group, mean age of 41.05 years, 13 females and 8 males. One hundred and eleven patients with psoriasis tested serologically, 80 (72.07\%) were seropositive compared with 7 positive volunteers (33.33\%; $\mathrm{P}=0.002)$. Forty-nine $(75.38 \%)$ patients with severe psoriasis were positive, $25(62.50 \%)$ with moderate psoriasis were positive and 6 $(28.57 \%)$ with mild psoriasis were positive $(\mathrm{P}=0.045)$. Study limitations: none.
\end{abstract}

ConClusions: $H$. pylori infection influences the development of psoriasis and severity of the disease.

Keywords: Psoriasis; Arthritis, Psoriatic; Helicobacter pylori; Antibodies

\section{INTRODUCTION}

Psoriasis is a chronic, non-contagious, of universal occurrence, inflammatory disease that affects skin and joints. ${ }^{1,2}$ In the skin, it is characterized by erythematous-squamous plaques, affecting mainly extensor surfaces of the limbs and scalp. The disorder is recurrent and has a prevalence of $2-3 \%$ in the world population. ${ }^{2,3}$ Its etiology is multifactorial, in which genetic and environmental factors lead to immunological dysfunction and characteristic inflammation. ${ }^{1,2}$

Psoriasis has an unknown cause, but some studies show a close correlation between disease and metabolic syndrome and cardiovascular diseases. ${ }^{4,5,6,7}$ Several microorganisms have also been identified as intensifiers of the disease. ${ }^{8}$ Recently, it has been suggested that Helicobacter pylori infection may contribute as a trigger for the development of psoriasis..$^{911}$

H. pylori has infected the human species for more than 50,000 years. ${ }^{11}$ It was isolated in 1982 by Barry Marshall and Robin
Warren. It is a gram-negative, microaerophilic, helicoidal bacterium that inhabits the gastric mucosa, and can cause peptic ulcer, gastritis and gastric cancer. ${ }^{12,13}$

In less developed countries, infection is acquired early in childhood through oral-fecal contact. Its prevalence rate reaches 80 $100 \%$ in adolescence and, if untreated, it persists throughout life. In contrast, in more developed countries, bacterial infection is acquired later in childhood or adolescence, and it is cured in about $10 \%$ of cases, reaching a prevalence peak of $50-70 \%$ during adulthood. ${ }^{13}$

The objective of this study was to determine the profile of seroprevalence of Helicobacter pylori in patients with clinical diagnosis of psoriasis treated in a period of six months at Ambulatório Amélio Marques of the Federal University of Uberlândia and to evaluate its association with the severity of the disease.

\section{Received on 28.05.2015}

Approved by the Advisory Board and accepted for publication on 05.03.2016

* Study conducted at Ambulatório Amélio Marques of the Universidade Federal de Uberlândia (UFU) - Uberlândia (MG), Brazil.

Financial Support: None.

Conflict of Interest: None.

Department of Clinical Medicine of the Universidade Federal de Uberlândia (UFU) - Uberlândia (MG), Brazil.

Department of Surgery of the Universidade Federal de Uberlândia (UFU) - Uberlândia (MG), Brazil.

Department of Dermatology of the Universidade Federal de Uberlândia (UFU) - Uberlândia (MG), Brazil.

(C2017 by Anais Brasileiros de Dermatologia 


\section{METHODS}

A total of 126 patients with psoriasis, with no personal history of gastrointestinal symptoms or at the time of the interview, attended at the psoriasis outpatient clinic (Ambulatório Amélio Marques, Federal University of Uberlândia) were followed prospectively for six months (from May to November 2014) after signing the informed consent form.

For each patient included in the study, a standard form was filled out with data: age, gender, weight, color, height, body mass index (BMI), comorbidities, time of disease evolution, lesion site and dermatological characteristics, degree of severity of psoriasis (PASI score), treatments performed and therapeutic response (data collected by patients' charts at the time of consultation).

Twenty-one volunteers without skin diseases and without personal history of gastrointestinal symptoms, with signed informed consent form, were included as control group. This group was formed by people of socioeconomic level similar to those of the patients and who were accompanying them during the consultations or who had been consulted in another ambulatory near the place.

Patients with psoriasis and controls underwent serology for H. pylori.

\section{PASI score (Psoriasis Area and Severity Index)}

PASI score is the gold standard for the classification of patients with psoriasis regarding the severity and extension of the disease. It considers the location of the lesions (head, trunk, upper and lower limbs), degree of erythema, desquamation and infiltration of plaques. For each region of the body, the surface area involved is graded from 1 to 6 , and each of the three parameters (erythema, infiltration and desquamation of plaques) is graded from 0 to 4 . The scores for each region, after being multiplied by a constant, are summed and result in the PASI score. Patients with PASI less than 5 are classified as having mild psoriasis. Patients with PASI between 5 and 10 have moderate disease and those with PASI greater than or equal to 10 have severe psoriasis. ${ }^{2}$.

\section{Serological Testing (Anti-IgG Antibodies)}

Patient contact with Helicobacter pylori was tested in patients and controls using the quantitative enzyme immunoassay method (Elisa test). The results used as standard are those recommended by the manufacturer, i.e.: positive, results greater than or equal to 1.1 $\mathrm{U} / \mathrm{ml}$; negative, results lower than $0.9 \mathrm{U} / \mathrm{ml}$; and undetermined, results between 0.9 and $1.1 \mathrm{U} / \mathrm{ml}$.

\section{Statistical analysis}

Patients were classified according to disease severity (mild, moderate or severe) and the prevalence profile of the presence or absence of bacterial infection in these patients was established. Statistical analysis of the quantitative variables (age, BMI and time of disease evolution) was performed by analysis of variance (ANOVA); for those following normality (age and BMI), through Kolmogorov-Smirnov test, and through the Kruskal-Wallis test to compare the mean rankings of the variables for those not following normality (disease evolution time). The Chi-square test was performed for the qualitative variables (gender, comorbidities, location of skin lesions, medications used by patients and serology). After verifying the global association between serology and psoriasis, the local association between these categories was tested by the analysis of the adjusted residues. The adjusted residue has a standard normal distribution, that is, mean equals zero and standard deviation equals one. Thus, if the adjusted residue is greater than 1.96, in absolute value, it can be said that there is evidence of significant association between the two categories. The larger the residue adjusted, the stronger the association between them.

All analyzes were performed using the IBM SPSS Statistics $20^{\circledR}$ program, and a statistically significant $\mathrm{P}<0.05$ was considered.

This study was approved by the Research Ethics Committee of the Hospital de Clínicas of the Federal University of Uberlândia under the number 633.053 (CAAE 19698113.1.0000.5152) in May 2014.

\section{RESULTS}

Of the 126 patients with psoriasis, 73 (57.94\%) were women and $53(42.06 \%)$ were men. The patients' ages ranged from 10 to 82 years (mean of 50.48 years, standard deviation [SD] of \pm 15.14 years). Of the 126 patients, 65 (51.59\%) had severe psoriasis; 40 (31.75\%) patients had moderate psoriasis; and 21 (16.67\%) had mild psoriasis. Median time of disease evolution in patients with severe, moderate and mild psoriasis was 13.50 years (IQR 11.00 years), 13.00 years (IQR 15.25 years) and 6.00 years (IQR 15.75 years; $P=0.142$ ). Comorbidities most commonly found in psoriatic patients, regardless the severity of the lesions, were systemic arterial hypertension (SAH), obesity and type 2 diabetes mellitus (DM2) (Table 1).

The control group consisted of 21 volunteers, aged between 10 and 75 years (mean of 41.05 years, $S D \pm 17.91$ years), 13 women and 8 men.

The site of involvement of skin lesions, regardless the severity of the disease, predominated in the lower limbs: $63.07 \%$ in severe patients, $75.00 \%$ in moderate patients and $61.90 \%$ in mild ones. Table 2 shows the relation between the sites of skin lesions involvement and the severity of psoriasis.

Serology was positive in $80(72.07 \%)$ patients with the disease and in 7 volunteers (33.33\%) in the control group (Graph 1). This difference between the seropositivity of patients and that of control group was statistically significant $(\mathrm{P}=0.002)$.

Seropositivity for H. pylori occurred in 49 (79.03\%) patients with severe psoriasis, in $25(69.45 \%)$ patients with moderate psoriasis, in $6(46.15 \%)$ patients with mild psoriasis and in 7 volunteers $(33.33 \%)$ of the control group. The chi-square test $\left(x^{2}\right)$ showed that there was a statistically significant difference between the groups when severity was related to serology $(\mathrm{P}=0.045)$. Table 3 represents the distribution of patients and control group volunteers for $\mathrm{H}$. pylori serology.

In Table 3, it can be seen, from the adjusted residues that patients with mild psoriasis and controls are positively associated with negative serology (adjusted residues of 2.9 and 3.2, respectively) and, consequently, negative association with positive serology (adjusted residues of -2.2 and -3.4 , respectively). This means that there is a tendency for the patient with negative serology to develop a milder picture of psoriasis. On the other hand, as shown in Table 3 , the adjusted residues show poor evidence when comparing the indeterminate serology with the severity of psoriasis. 
TABLE 1: Distribution of patients regarding disease severity, mean age, gender, time of disease evolution, mean BMI, comorbidities and medications used

\begin{tabular}{|c|c|c|c|c|c|c|}
\hline & \multicolumn{3}{|c|}{ Psoriasis } & \multirow[t]{2}{*}{ Controls } & \multirow[t]{2}{*}{ p-value } \\
\hline & & Severe & Moderate & Mild & & \\
\hline \multicolumn{2}{|c|}{ Number of patients (\%) } & & $65(51.59 \%)$ & $40(31.75 \%)$ & $21(16.67 \%)$ & 21 \\
\hline \multirow{2}{*}{\multicolumn{2}{|c|}{ Mean age (years) }} & 50.62 & 51.65 & 47.81 & 41.05 & $\mathrm{P}=0.642$ \\
\hline & & \pm 14.41 & \pm 14.64 & \pm 18.43 & \pm 17.90 & (ANOVA) \\
\hline \multirow[t]{2}{*}{ Gender } & Women & $32(49.23 \%)$ & $15(37.50 \%)$ & $6(28.58 \%)$ & $8(38.09 \%)$ & $\mathrm{P}=0.194(\chi 2)$ \\
\hline & Men & $33(50.77 \%)$ & $25(62.50 \%)$ & $15(71.42 \%)$ & $13(60.91 \%)$ & \\
\hline \multirow{2}{*}{\multicolumn{2}{|c|}{ Time of evolution (median in years) }} & 13.5 & 13.0 & 6.0 & & $\mathrm{P}=0.142$ \\
\hline & & IQR 11.00 & IQR 15.25 & IQR 15.75 & & (Kruskal Wallis) \\
\hline \multirow{2}{*}{\multicolumn{2}{|c|}{ Mean BMI $\left(\mathrm{kg} / \mathrm{m}^{2}\right)$}} & 28.03 & 27.55 & $26.55 \pm 4.82$ & & $\mathrm{P}=0.710$ \\
\hline & & \pm 6.69 & \pm 6.47 & \pm 4.82 & & (ANOVA) \\
\hline \multicolumn{7}{|c|}{ Comorbidities } \\
\hline & $\mathrm{SAH}$ & $26(40.00 \%)$ & $12(30.00 \%)$ & $8(38.09 \%)$ & & $\mathrm{P}=0.578\left(\chi^{2}\right)$ \\
\hline & Obesity & $19(29.23 \%)$ & $10(25.00 \%)$ & $4(19.04 \%)$ & & $\mathrm{P}=0.639\left(\chi^{2}\right)$ \\
\hline & DM2 & $15(23.07 \%)$ & $7(17.50 \%)$ & $4(19.04 \%)$ & & $\mathrm{P}=0.775\left(\chi^{2}\right)$ \\
\hline & Hypothyroidism & $3(4.61 \%)$ & $1(2.50 \%)$ & $0(0 \%)$ & & $\mathrm{P}=0.552\left(\chi^{2}\right)$ \\
\hline & None & $14(21.53 \%)$ & $15(37.50 \%)$ & $8(38.09 \%)$ & & $\mathrm{P}=0.935\left(\chi^{2}\right)$ \\
\hline & Other & $20(30.77 \%)$ & $19(47.50 \%)$ & $9(42.85 \%)$ & & $\mathrm{P}=0.166\left(\chi^{2}\right)$ \\
\hline \multicolumn{7}{|c|}{ Medication } \\
\hline & Topic & $16(24.61 \%)$ & $14(35 \%)$ & $21(100 \%)$ & & $\mathrm{P}<0.001^{*}(\chi 2)$ \\
\hline & Acitretin & $36(55.38 \%)$ & $20(50 \%)$ & $1(4.76 \%)$ & & $\mathrm{P}<0.001^{*}\left(\chi^{2}\right)$ \\
\hline & MTX & $39(60 \%)$ & $28(70 \%)$ & $0(0 \%)$ & & $\mathrm{P}<0.001^{*}(\chi 2)$ \\
\hline & Immunobiological & $16(24.61 \%)$ & $0(0 \%)$ & $0(0 \%)$ & & $P<0.001^{*}(\chi 2)$ \\
\hline
\end{tabular}

SAH: Systemic arterial hypertension; DM2: Type 2 diabetes mellitus; BMI: body mass index; MTX: methotrexate; \pm : standard deviation; IQR: interquartile range * Statistically significant value $(\mathrm{p}<0.05) ; \chi 2$ : Chi-square test

TABLE 2: Place of involvement of skin lesions in relation to the severity of psoriasis

\begin{tabular}{lllll}
\hline Location of skin lesions & \multicolumn{4}{c}{ Psoriasis } \\
\cline { 2 - 5 } & Severe & Moderate & Mild & p-value $(\chi 2)$ \\
\hline Lower limbs (\%) & $41(63.07 \%)$ & $30(75.00 \%)$ & $13(61.90 \%)$ & 0.183 \\
Upper limbs (\%) & $39(60.00 \%)$ & $26(65.00 \%)$ & $12(57.14 \%)$ & 0.499 \\
Trunk (\%) & $28(43.07 \%)$ & $22(55.00 \%)$ & $9(42.85 \%)$ & $0.009^{*}$ \\
Scalp (\%) & $25(38.46 \%)$ & $26(65.00 \%)$ & $7(33.33 \%)$ & $0.013^{*}$ \\
Nail (\%) & $4(6.15 \%)$ & $3(7.50 \%)$ & $1(4.76 \%)$ & 0.913 \\
Joint (\%) & $12(18.46 \%)$ & $0(0 \%)$ & $0(0 \%)$ & $0.002^{*}$ \\
Total of patients & 65 & 40 & 21 & 0.199 \\
\hline
\end{tabular}

* Statistically significant value $(\mathrm{p}<0.05)$

TABLE 3: Relation of anti-H. pylori serology with the severity of the disease

\begin{tabular}{|c|c|c|c|c|c|}
\hline \multirow[t]{2}{*}{ Serology } & \multicolumn{3}{|c|}{ Psoriasis } & \multirow[t]{2}{*}{ Controls } & \multirow[t]{2}{*}{ p-value $(\chi 2)$} \\
\hline & Severe & Moderate & Mild & & \\
\hline Positive & $49(79.03 \%)$ & $25(69.45 \%)$ & $6(46.15 \%)$ & $7(33.33 \%)$ & $\mathrm{P}=0.045^{*}$ \\
\hline Adjusted residue & 1.8 & 0.4 & -2.2 & -3.4 & \\
\hline Negative & $10(16.12 \%)$ & $8(22.22 \%)$ & $7(53.85 \%)$ & $12(57.15 \%)$ & \\
\hline Adjusted residue & -1.8 & -0.1 & -2.9 & -3.2 & \\
\hline Undetermined & $3(4.83 \%)$ & $3(8.33 \%)$ & $0(0 \%)$ & $2(9.52 \%)$ & \\
\hline Adjusted residue & -0.3 & 0.9 & -0.9 & 0.7 & \\
\hline Total & 62 & 36 & 13 & 21 & \\
\hline
\end{tabular}

Obs: Of the 65 patients with severe psoriasis. 3 did not collect serology.; Of the 40 patients with moderate psoriasis, 4 did not collect serology.; Of the 21 patients with mild psoriasis, 8 did not receive serology.

\section{DISCUSSION}

It has been well documented that patients with psoriasis are more likely to develop metabolic syndrome, in addition to systemic arterial hypertension, type 2 diabetes mellitus and obesity, since these conditions increase Th1 proinflammatory cytokines, leading to a range of actions in the insulin signaling, lipid metabolism and adipogenesis. ${ }^{6,7,14,15,16}$ In our study, the comorbidities most commonly found in psoriatic patients were systemic arterial hypertension, obesity and type 2 diabetes mellitus, findings that are in agreement with the international literature. 


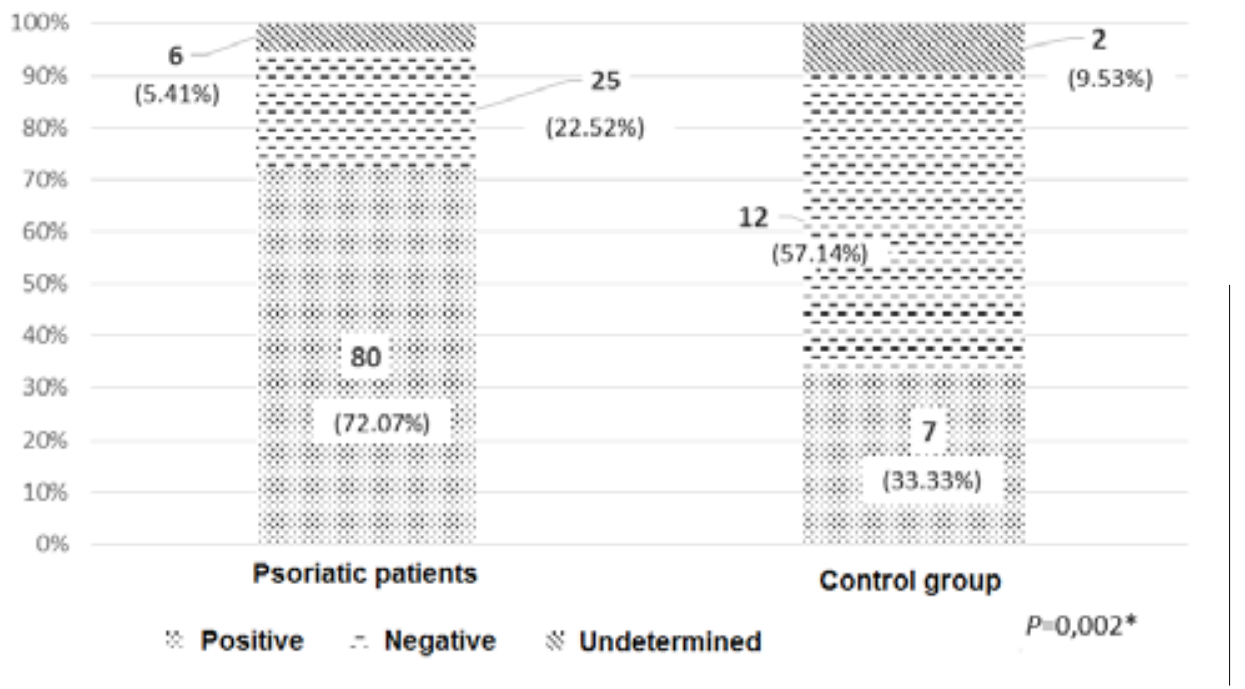

GRAPH 1:

Comparison between patients and controls with serology for H. pylori.
The present study also showed a higher prevalence of lesions in the lower and upper limbs. This is probably due to the fact that plaque psoriasis is the most frequent subtype and most commonly affects the sites of greatest trauma in the human body that are the extensor surfaces of the limbs. ${ }^{2}$

The difference found in the percentage of H. pylori infection in this study in psoriatic patients and controls shows a probable association between the disease and the bacterium. Likewise, this higher percentage among patients with severe psoriasis compared with patients with mild or moderate disease suggests that there is also a relation of severity with infection.

These findings are consistent with several studies that have also linked psoriasis to H. pylori. Qayoom e Ahmad ${ }^{17}$ detected the presence of anti-H. pylori antibodies in $40 \%$ of patients with psoriasis and $10 \%$ in the control group (healthy subjects without gastrointestinal complaints) and concluded that $j 107$

$j$ plays a causal role in the pathogenesis of psoriasis. Hübner and Tenbaum, in a study published in 2008, reported complete improvement of palmoplantar psoriasis in one patient after $H$. pylori eradication. Other studies have also confirmed the beneficial effect of $H$. pylori eradication in various dermatological diseases, such as chronic urticaria ${ }^{21}$, idiopathic thrombocytopenic purpura, rosacea, and even psoriasis. ${ }^{14,18-26}$

However, Fabrizi et al., in their study with 49 patients (ages between 5 and 19 years), in which 20 had psoriasis and 29 were controls without skin diseases, tested all patients for $H$. pylori through the respiratory urease test. ${ }^{27}$ Of the 20 psoriatic patients, $10 \%$ presented positive test. Of the 29 controls, without any skin disease, $17 \%$ showed a positive result. They concluded that there is a low prevalence of Helicobacter pylori infection in psoriatic children and adolescents, and that this relation is not different from that found in children without skin diseases.

As in the present study, Fathy et al. compared 20 plaque psoriasis patients with 20 healthy individuals, age-matched and gender-matched, and tested H. pylori using the Elisa test. ${ }^{28}$ The mean prevalence of seropositivity in patients with psoriasis was signifi- cantly higher when compared with controls, and the high values correlated with the severity of the disease. They concluded that larger studies and a more detailed investigation regarding the eradication of H. pylori in psoriatic patients with positive serology are necessary for definitive confirmation.

Another important study that should be remembered was the one conducted by Onsun et al., in which 300 patients with plaque psoriasis and 150 healthy controls were evaluated to determine the prevalence of $H$. pylori seropositivity in patients with psoriasis, the relation between PASI and H. pylori infection, and the impact of bacterial infection in the response to treatment. ${ }^{29}$ Fecal samples of patient and controls were tested for the presence of bacterial antigens and disease severity was assessed by PASI score in all patients. Seventy-five psoriasis and $H$. pylori-infected patients were divided into three groups with 25 patients: the first group received treatment with acitretin and antibiotic therapy against $H$. pylori; the second group received only acitretin; and the third group received only treatment for H. Pylori. Eight weeks later, the patients' PASIs were measured and compared. The prevalence of H. pylori infection was $61.3 \%$ in patients with psoriasis and $59.3 \%$ in the control group $(\mathrm{P}>0.05)$. The mean PASI score was statistically higher in patients with psoriasis and H. pylori positive compared with patients with psoriasis and $H$. pylori negative. Patients receiving acitretin and antibiotic therapy showed a faster improvement than those receiving acitretin alone $(\mathrm{P}<0.05)$. Patients who received only antibiotic therapy also showed significant improvement compared with controls $(\mathrm{P}<0.001)$. This study suggests that $H$. pylori infection plays an important role in the severity of psoriasis, and that its eradication increases the efficacy of treatment of the disease.

While different types of infections have been implicated as causes of psoriasis, studies that associate H. pylori as the cause of the disease are still very recent. What makes this association an interesting research is the chronic, endemic and asymptomatic nature of $H$. pylori infection. ${ }^{14}$ How the bacterium can cause psoriasis is not known yet, as well as it is still far from been clarified whether $H$. pylori can cause skin disease. 
The role of $H$. pylori in the pathogenesis of extradigestive manifestations is based on the fact that the local inflammation caused by the bacterium has systemic effects. The bacterium not only colonizes the gastric mucosa but induces a strong inflammatory response with the release of several cytotoxic substances. ${ }^{30}$ Gastric infection with $H$. pylori is a chronic process that can last for decades, and persistent infection induces chronic inflammation and an immune response that can cause lesions both locally and remotely. Systemic effects involve increased gastric mucosal permeability to food antigens, immunomodulation, autoimmune mechanism, and impairment of vascular integrity. The diversity of H. pylori immunopathogenesis can occur due to an imbalance in Th1 and Th2 response. Activation of T-cell superantigens occurs because $H$. pylori secretes enterotoxins that bind to a T-cell receptor and induce expression of a skin homing receptor and of a cutaneous lymphocytic antigen in the T-cell. ${ }^{8,25,31}$

\section{REFERENCES}

1. Langham S, Langham J, Goertz HP, Ratcliffe M.. Large-scale, prospective, observational studies in patients with psoriasis and psoriatic arthritis: a systematic and critical review. BMC Med Res Methodol. 2011;11:32.

2. Sociedade Brasileira de Dermatologia. Consenso brasileiro de psoríase 2012. Guias de avaliação e tratamento. 2. ed. Rio de Janeiro: Sociedade Brasileira de Dermatologia; 2012

3. Suite M. The epidemiology of psoriasis in a dermatology clinic in a general hospital in Port-of-Spain, Trinidad and Tobago, West Indies. West Indian Med J. 2006;55:399-402.

4. Abuabara K, Azfar RS, Shin DB, Neimann AL, Troxel AB, Gelfand JM. Causespecific mortality in patients with severe psoriasis: a population-based cohort study in the U.K. Br J Dermatol. 2010;163:586-92.

5. Maradit-Kremers H, Icen M, Ernste FC, Dierkhising RA, McEvoy MT. Disease severity and therapy as predictors of cardiovascular risk in psoriasis: a populationbased cohort study. J Eur Acad Dermatol Venereol. 2012;26:336-43.

6. Armstrong AW, Harskamp CT, Armstrong EJ. Psoriasis and metabolic syndrome: a systematic review and meta-analysis of observational studies. J Am Acad Dermatol. 2013;68:654-62.

7. Bohr UR, Annibale B, Franceschi F, Roccarina D, Gasbarrini A. Extragastric manifestations of Helicobacter pylori infection - other Helicobacters. Helicobacter. 2007;12:45-53.

8. Fry L, Baker BS. Triggering psoriasis: the role of infections and medications. Clin Dermatol. 2007;25:606-15.

9. Rosenberg EW, Noah PW, Skinner RB Jr. Microorganisms and psoriasis. J Nat Med Assoc. 1994;86:305-10.

10. Halasz, C.L. Helicobacter pylori antibodies in patients with psoriasis. Arch Dermatol. 1996;132:95-6.

11. Linz B, Balloux F, Moodley Y, Manica A, Liu H, Roumagnac P, et al. An African origin for the intimate association between humans and Helicobacter pylori. N Nature. 2007:445:915-8
The hypothesis of Fathy et al. is that H. pylori could be at least the triggering factor of psoriasis, particularly the chronic infectious agent that maintains skin disease ${ }^{28}$ However, the etiology of psoriasis seems multifactorial and the idea remains that $H$. pylori is the trigger for the disease in susceptible individuals. An autoimmune mechanism has been suggested in psoriasis and H. pylori has been associated with autoimmune processes in susceptible patients.

\section{CONCLUSION}

Our results agree with those in the literature on the fact that Helicobacter pylori infection is higher in psoriatic patients and may interfere with the severity of psoriasis.
12. Marshall BJ, Warren JR. Unidentified curved bacilli in the stomach of patients with gastritis and peptic ulceration. Lancet. 1984;1:1311-5.

13. Mbulaiteye SM, Hisada M, El-Omar EM. Helicobacter pylori associated global gastric cancer burden. Front Biosci (Landmark Ed). 2009;14:1490-504.

14. Leontiadis Gl, Sharma VK, Howden CW. Non-gastrointestinal tract associations of Helicobacter pylori infection. Arch Intern Med. 1999;159:925-40.

15. Franceschi F, Tortora A, Gasbarrini G, Gasbarrini A. Helicobacter pylori and extragastric diseases. Helicobacter. $2014 ; 19: 52-8$

16. Voiculescu VM, Lupu M, Papagheorghe L, Giurcaneanu C, Micu E. Psoriasis and Metabolic Syndrome - scientific evidence and therapeutic implications. J Med Life. 2014;7:468-71.

17. Qayoom S, Ahmad QM. Psoriasis and Helicobacter pylori. Indian J Dermatol Venereol Leprol. 2003;69:133-4.

18. Martin Hübner A, Tenbaum SP. Complete remission of palmoplantar psoriasis through Helicobacter pylori eradication: a case report. Clin Exp Dermatol. 2008;33:339-40.

19. Shiotani A, Okada K, Yanaoka K, Itoh H, Nishioka S, Sakurane M, et al. Beneficial effect of Helicobacter pylori eradication in dermatologic diseases. Helicobacter. 2001;6:60-5.

20. Sakurane M, Shiotani A, Furukawa F. Therapeutic effects of antibacterial treatment for intractable skin diseases in Helicobacter pylori-positive Japanese patients. J Dermatol. 2002;29:23-7.

21. Federman DG, Kirsner RS, Moriarty JP, Concato J. The effect of antibiotic therapy for patients infected with Helicobacter pylori who have chronic urticaria. J Am Acad Dermatol. 2003;49:861-4.

22. Hernando-Harder AC, Booken N, Goerdt S, Singer MV, Harder H. Helicobacter pylori infection and dermatologic diseases. Eur J Dermatol. 2009;19:431-44.

23. Kutlubay Z, Zara T, Engin B, Serdaroğlu S, Tüzün Y, Yilmaz E, et al. Helicobacter pylori infection and skin disorders. Hong Kong Med J. 2014;20:317-24. 
24. Ali M, Whitehead M. Clearance of chronic psoriasis after eradication therapy for Helicobacter pylori infection. J Eur Acad Dermatol Venereol. 2008;22:753-4.

25. Magen E, Delgado JS. Helicobacter pylori and skin autoimmune diseases. World J Gastroenterol. 2014;20:1510-6.

26. Sáez-Rodríguez M, Noda-Cabrera A, García-Bustínduy M, Guimerá-Martín-Neda F, Dorta-Alom S, Escoda-García M, et al. Palmoplantar pustulosis associated with gastric Helicobacter pylori infection. Clin Exp Dermatol. 2002;27:720.

27. Fabrizi G, Carbone A, Lippi ME, Anti M, Gasbarrini G. Lack of evidence of relationship between Helicobacter pylori infection and psoriasis in childhood. Arch Dermatol. 2001;137:1529.

28. Fathy G, Said M, Abdel-Raheem SM, Sanad, H. Helicobacter Pylori Infection: A possible predisposing factor in chronic plaque-type psoriasis. J Egypt Women Dermatol Soc. 2010;7:39-43.

29. Onsun N, Arda Ulusal H, Su O, Beycan I, Biyik Ozkaya D, Senocak M. Impact of Helicobacter pylori infection on severity of psoriasis and response to treatment. Eur J Dermatol. 2012;22:117-20.

30. Testerman TL, Morris J. Beyond the stomach: an updated view of Helicobacter pylori pathogenesis, diagnosis, and treatment. World J Gastroenterol. 2014;20:12781-808.

31. Versalovic J. Helicobacter pylori Pathology and Diagnostic Strategies. Am J Clin Pathol. 2003;119:403-12.

\author{
MAILING ADDRESS: \\ Priscila Miranda Diogo Mesquita \\ Av. Pará, 1720 \\ Umuarama \\ 38405-320 - Uberlândia - MG \\ Brazil \\ Email:primdiogo@yahoo.com.br
}

How to cite this article: Mesquita PMD, Diogo-Filho Augusto, Jorge MT, Berbert ALCV, Mantese SAO, Rodrigues JJ. Relationship of Helicobacter pylori seroprevalence with the occurrence and severity of psoriasis. An Bras Dermatol. 2017;92(1):52-7. 